\title{
APLIKASI PROGRAMMABLE LOGIC CONTROLLER (PLC) PADA SISTEM KONTROL PROSES PENGELASAN INNER DAN OUTER TABUNG IRADIASI
}

\author{
I WAYAN W., SOFYAN SORI, JAKARIA, ARTADI HERU W., MUlyONO \\ Pusat Radioisotop dan Radiofarmaka - BATAN \\ Kawasan Puspiptek Gd. 11 Serpong Tangerang 15310
}

\begin{abstract}
Abstrak
APLIKASI PROGRAMMABLE LOGIC CONTROLLER (PLC) PADA SISTEM KONTROL PROSES PENGELASAN INNER DAN OUTER TABUNG IRADIASI. Pada proses pengelasan inner dan outer tabung iradiasi, diperlukan sumber daya manusia yang handal sehingga hasil pengelasan memenuhi persyaratan yang ditetapkan untuk dapat diiradiasi di reaktor nuklir. Karena adanya keterbatasan sumber daya manusia yang mampu melakukan pengelasan tabung iradiasi secara sempurna, maka dibuat sistem kontrol proses pengelasan inner dan outer tabung iradiasi. Dengan sistem kontrol tersebut maka pengelasan tabung iradiasi dapat dilakukan secara otomatis. Metoda yang digunakan yaitu dengan menggunakan Programmable Logic Controller (PLC) yang difungsikan untuk mengatur proses pengelasan secara otomatis melalui program yang ditanamkan di dalamnya. Hasil yang diperoleh berupa unit kontrol yang telah diuji secara simulasi, kemudian dirangkai pada unit mesin las, dan selanjutnya dilakukan uji pengelasan terhadap tabung iradiasi. Pada hasil pengelasan dilakukan juga uji kebocoran dengan metode bubble test. Sistem kontrol dapat dinyatakan berfungsi dengan baik, karena semua langkah dalam proses pengelasan sudah terpenuhi. Hasil pengelasan yang kurang maksimal lebih besar diakibatkan oleh kondisi tabung iradiasi yang kurang sempurna seperti bentuk kurang simetris dan permukaan tidak bersih, serta kondisi bagian mekanik pada pemutar tabung iradiasi yang tidak presisi.
\end{abstract}

Kata kunci: Sistem kontrol, PLC, Pengelasan, Tabung iradiasi

\begin{abstract}
APLICATION OF PROGRAMMABLE LOGIC CONTROLLER (PLC) IN CONTROL SYSTEM FOR INNER AND OUTER WELDING PROCESSES

OF IRRADIATION CHAMBER. Inner and outer welding processes of irradiation chamber require reliable human resources so that the welding results will meet the standardized requirements for irradiation with nuclear reactor. The control system of the inner and outer welding processes of the irradiation chamber was made due to limited human resources who are able to weld the irradiation chamber perfectly. The irradiation chamber's welding is expected to be done automatically by using the system control. The system is created by using Programmable Logic Controller (PLC) which function is to automatically organize the welding processes through the codes attached there in. The system comprises of a control unit which has been tested in a simulation, and then attached in a welding machine unit, and subsequently tested for welding the irradiation chamber. The result of the welding is also tested for its
\end{abstract}


leak using bubble test. As all procedures are well followed in the welding processes, the control system is found to work properly. The welding results which are not optimum are mainly due to imperfect irradiation tubes, such as the lack of symmetry in the tube's geometry, unclean surface, as well as the condition of the unprecised mechanical part of the tubes.

Keywords: Control system, PLC, Welding, Irradiation chamber

\section{PENDAHULUAN}

Pusat Radioisotop dan Radiofarmaka (PRR) memiliki berbagai macam fasilitas yang terkait dengan proses iradiasi nuklir, salah satunya adalah tabung iradiasi ${ }^{[1,2]}$. PRR mempunyai fasilitas untuk membuat tabung iradiasi tersebut. Dalam proses pembuatan terdapat berbagai macam langkah mulai dari persiapan bahan (tabung aluminium), pengerjaan bentuk tabung (pemotongan bahan, bubut, milling, dan lain-lain), pengelasan, tahap pengujian sampai siap digunakan sebagai wadah materi yang akan diiradiasi. Pada tahap pengelasan, PRR mempunyai kendala pada penyediaan sumber daya manusia (SDM), dimana pada saat ini hanya terdapat dua karyawan yang mampu melakukan pengelasan tersebut. Ada kemungkinan kedua karyawan tersebut berhalangan sehingga pengelasan tabung iradiasi akan tertunda.

Selama ini proses pengelasan dilakukan secara manual. Proses pengelasan secara manual mempunyai risiko kecelakaan yang besar terhadap operator mesin las. Risiko tersebut dapat terjadi karena operator bersentuhan langsung dengan mesin las serta berada pada jarak yang sangat dekat dengan benda kerja. Dalam kondisi seperti itu mesin las dan benda kerja dapat memberikan panas sampai dengan ratusan derajat celcius.

Kurangnya SDM dan risiko yang cukup besar pada pengelasan tabung iradiasi secara manual, menimbulkan gagasan untuk melakukan proses pengelasan secara otomatis. Gagasan ini merupakan gagasan baru yang belum pernah ada sebelumnya di PRR. Pada saat ini sudah dilakukan realisasinya, dimana pekerjaan mekanik telah dilaksanakan yaitu pada pembuatan meja kerja sebagai tempat benda kerja (tabung iradiasi) serta tempat komponen pendukung lainnya. Agar dapat bekerja secara otomatis, maka dibuat rangkaian kontrol yang mengatur operasional proses pengelasan tabung iradiasi dengan menggunakan PLC sebagai basisnya. PLC akan mengatur proses operasi sebagaimana yang dibuat dalam diagram alir (flow (hart $)^{[3]}$. 


\section{LANDASAN TEORI}

\section{Programmable Logic Controller (PLC)}

$P L C$ adalah suatu alat kontrol dimana operasionalnya dapat dikontrol dengan sebuah program yang ditanamkan didalamnya ${ }^{[3]}$. Dibandingkan dengan alat kontrol konvensional, PLC mempunyai kemudahan karena modifikasi dapat dilakukan tanpa harus merubah instalasi. Modifikasi hanya dilakukan pada program. Program yang sering digunakan adalah program diagram tangga (Ladder Diagram). Dalam diagram tangga akan terlihat logika proses kontrol sesuai dengan flow chart yang diinginkan.

\section{Tabung Iradiasi}

Tabung iradiasi merupakan wadah yang digunakan sebagai tempat zat atau sasaran (target) yang akan diiradiasi. Iradiasi sendiri merupakan tindakan yang dilakukan (proses) agar suatu materi menjadi aktif atau mengandung radiasi. Tabung iradiasi terbuat dari bahan aluminium dengan tingkat kemurnian yang tinggi yaitu sekitar $99 \%$. Terdapat 2 jenis tabung iradiasi yaitu outer capsule dan inner capsule. Sasaran yang akan diiradiasi diletakkan di dalam inner capsule. Kemudian inner capsule dimasukkan kedalam outer capsule untuk diiradiasi di dalam reaktor.

\section{TATA KERJA}

\section{Bahan dan Peralatan}

Bahan dan peralatan yang digunakan adalah PLC merek OMRON tipe SYSMAC CPMIA-40CDR-A dilengkapi dengan syswin sebagai software pendukung serta komputer sebagai sarana penunjang dalam pembuatan program, tabung iradiasi (inner dan outer) sebagai benda kerja yang akan dilas yang terbuat dari bahan aluminium, Mesin las TIG merek TELWIN tipe SuperTIG 180 AC/DC, Pemegang benda kerja (three jaw chuck) yaitu alat yang biasa digunakan pada mesin bubut yang berfungsi memegang benda kerja, Motor pemutar benda kerja dengan tegangan kerja 110 VDC yang berfungsi untuk memutar three jaw chuck, Pengatur kecepatan motor pemutar benda kerja dengan output tegangan yang bervariasi dari 0 - 110 VDC, Exhaust Fan dengan tegangan kerja 220 VAC yang berfungsi menghisap asap saat pengelasan dan membuangnya keluar melalui pipa pembuangan. Selain itu, diperlukan beberapa komponen masukan bagi PLC seperti; Switch Start pada pengelasan inner capsule, Switch Stop/Reset, Switch Start pada pengelasan Outer Capsule. 


\section{Blok Diagram}

Secara manual blok diagram pada proses pengelasan tabung iradiasi sangat sederhana seperti Gambar 1. Kemudian, dengan menggunakan PLC dapat dibuat proses pengelasan menjadi otomatis. Beberapa komponen ditambahkan guna menunjang sistem pengelasan secara otomatis. Komponen tersebut antara lain; Exhaust fan, Speed control, Motor, dan komponen input PLC (switchs). Blok diagram proses pengelasan secara otomatis dapat dilihat pada Gambar 2.

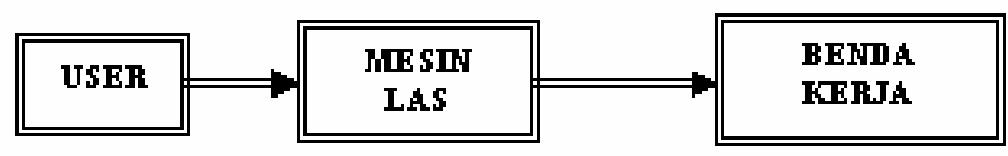

Gambar 1. Blok Diagram Pengelasan Secara Manual

\section{Diagram Alir}

Diagram alir mencerminkan langkah-langkah yang dilakukan dalam proses pengelasan secara otomatis. Setiap langkah tersebut diatur oleh PLC sesuai dengan program yang ditanamkan. Deskripsi langkah-langkah pada proses pengelasan secara otomatis adalah sebagai berikut; pertama, terdapat jenis operasi otomatis atau manual. Pada posisi manual fungsi mesin las dan exhaust fan dapat digunakan. Pada posisi otomatis pengoperasian dilakukan hanya dengan menekan tombol start sehingga menghidupkan torch dan exhaust fan. Motor pemutar benda kerja hidup oleh delay waktu pelelehan. Kedua, jika ketiga komponen tersebut $\mathrm{ON}($ torch mesin las, exahaust fan, dan motor pemutar benda kerja), maka proses pengelasan dapat berjalan. Ketiga, proses akan berhenti apabila siklus $450{ }^{\circ}$ tercapai $\left(1\right.$ siklus $=360{ }^{\circ}$ ditambah $90^{\circ}$ ), tetapi exhaust fan tidak langsung berhenti, menunggu delay 15 detik untuk menghilangkan sisa asap akibat proses pengelasan. Terdapat interlock antara proses pengelasan inner capsule dan proses pengelasan outer capsule. Tombol stop juga berfungsi sebagai reset untuk fungsi interlock. Diagram alir yang dihasilkan dapat dilihat pada Lampiran.

\section{Diagram Tangga}

Diagram tangga yang dihasilkan dapat dilihat pada Gambar 3. 


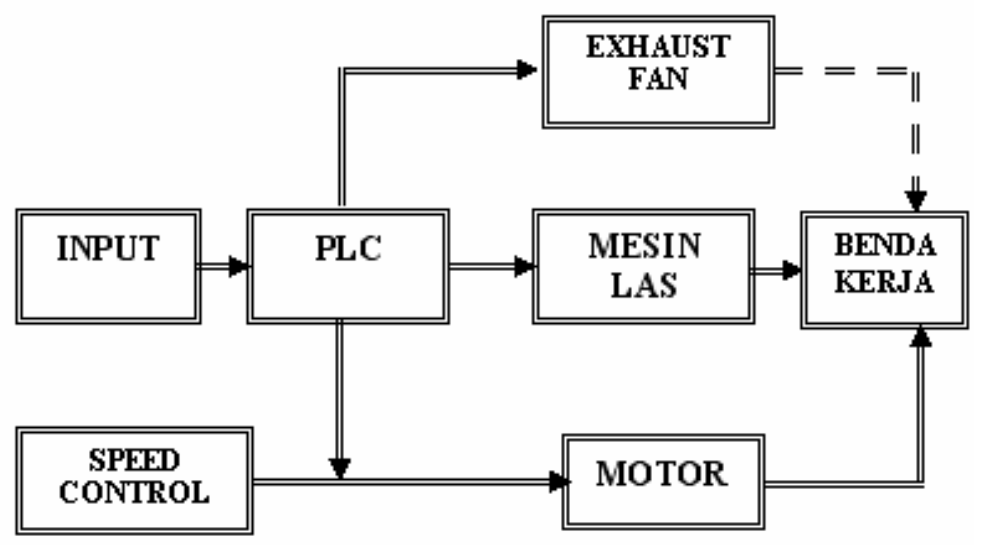

Gambar 2. Blok Diagram Pengelasan Secara Otomatis

\section{Menanam Program}

Untuk lebih memahami penanaman program ke $P L C$, maka perlu diperhatikan tampilan monitor pada software syswin saat software tersebut dibuka seperti terlihat pada Gambar 4.

Pada tampilan terlihat menu-menu utama pada bagian atas layar. Perintah down load program to PLC tersimpan pada menu "online". Down load dinyatakan berhasil jika keluar tulisan "successful" pada layar monitor. Jika gagal maka perlu dilakukan pemeriksaan ulang. Ada kemungkinan belum adanya koneksi antara $P L C$ dengan komputer, atau $P L C$ sedang berada pada RUN mode atau Monitor mode. Jika berada pada mode tersebut maka $P L C$ harus dipindahkan ke STOP mode.

\section{Simulasi}

Pada Gambar 5 dapat dilihat bahwa komponen-komponen output digantikan oleh lampu-lampu yang mewakili proses yang terjadi pada PLC. Simulasi ini bertujuan untuk menghindari kesalahan yang dapat mengakibatkan kerusakan pada komponen input, output, serta PLC itu sendiri.

Pengkabelan yang dilakukan adalah membuat jalur-jalur kabel yang merangkai atau menghubungkan PLC terhadap input dan output yang sebenarnya. Dari simulasi tersebut maka komponen output yang berupa lampu-lampu kemudian digantikan dengan komponen output yang nyata. Pemasangan komponen input dan output dilakukan pada terminal-terminal yang sudah disediakan pada papan panel kontrol. 


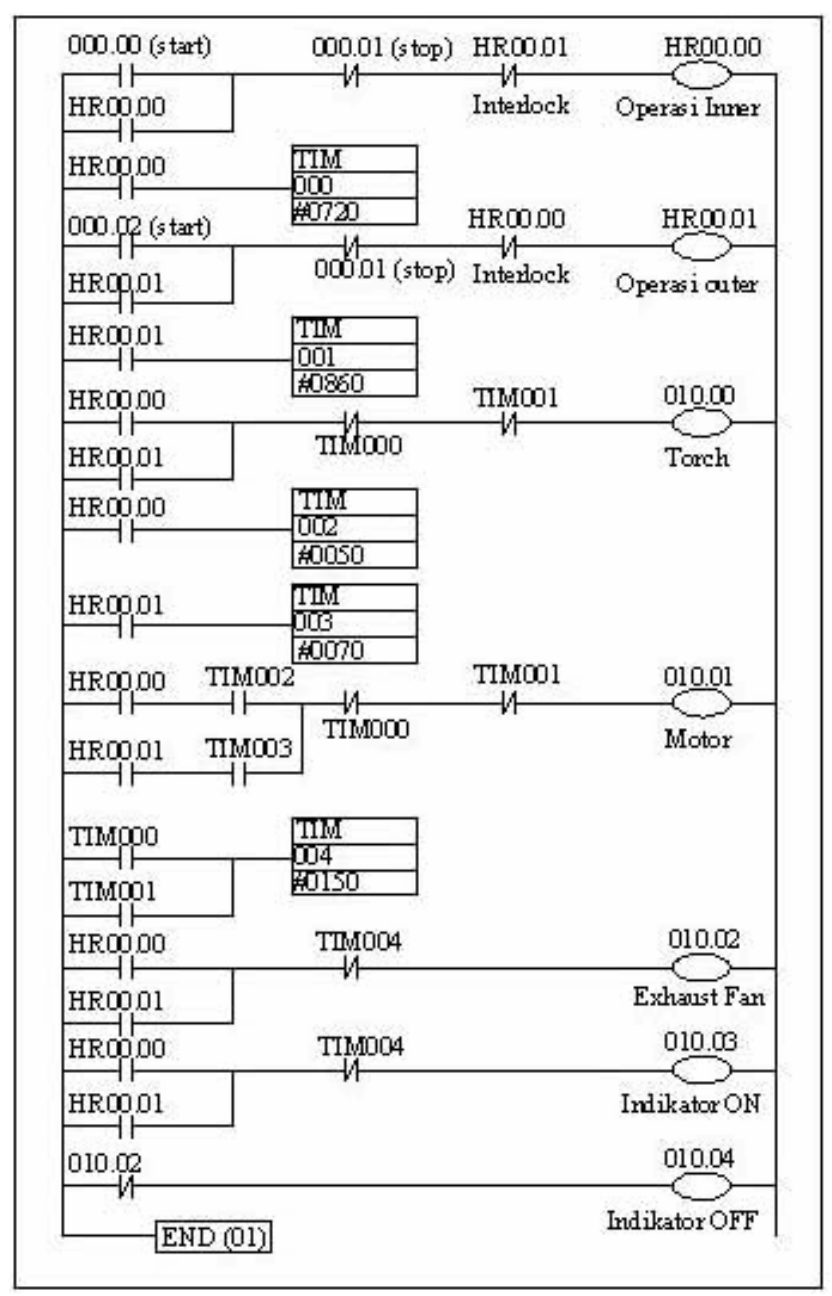

Gambar 3. Diagram Tangga

\section{HASIL DAN PEMBAHASAN}

\section{Uji Fungsi Sistem Kontrol}

Setelah instalasi panel kontrol, kemudian dilakukan uji fungsi sesuai diagram alir. Fungsi tersebut dapat berjalan sesuai dengan diagram alir. Kemudian dilakukan uji fungsi pengelasan serta pengaturan beberapa parameter yang disesuaikan dengan jenis benda kerjanya (inner capsule atau outer capsule). Parameter tersebut dapat dilihat pada Tabel 1. 


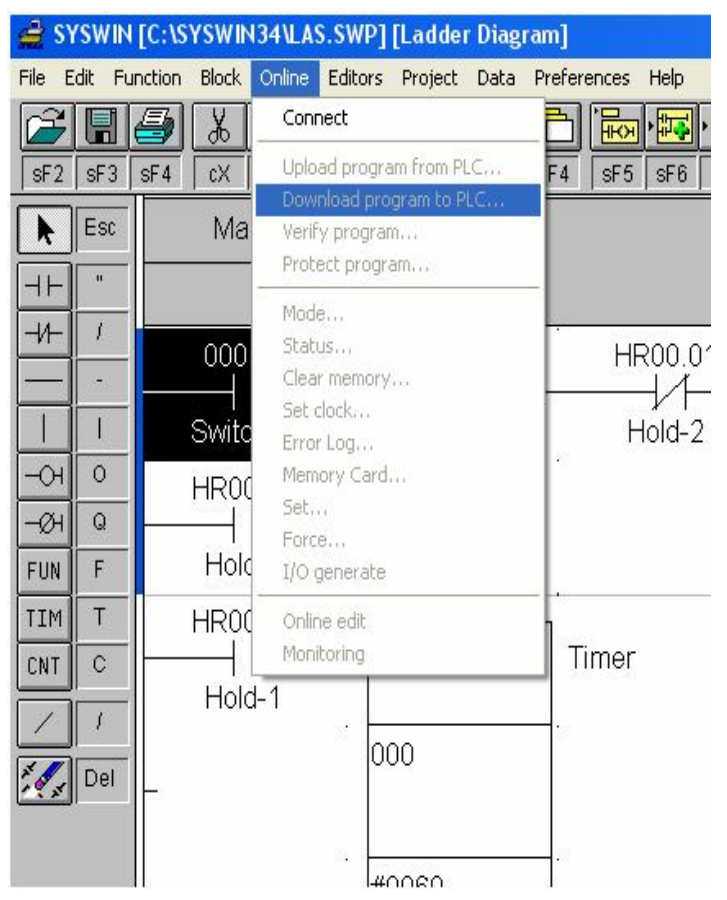

Gambar 4. Tampilan Monitor untuk Down Load Program ke PLC

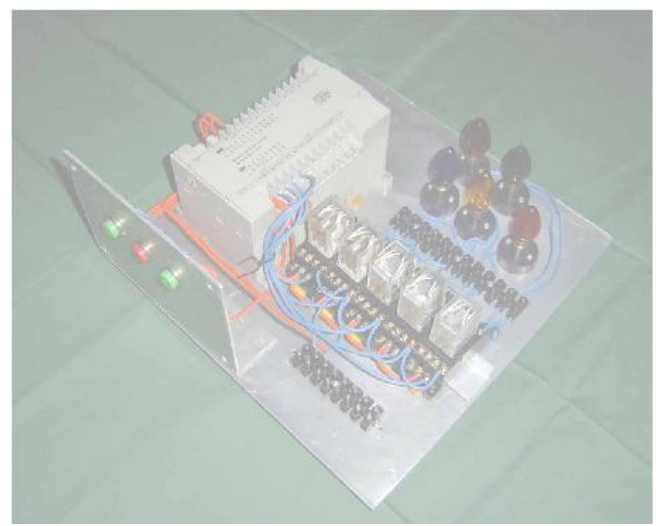

Gambar 5. Bentuk Rangkaian Kontrol yang Dihasilkan dan Dilengkapi dengan Simulasi

\section{Tabung Iradiasi Hasil Pengelasan}

Tabung iradiasi hasil pengelasan secara otomatis dapat dilihat pada Gambar 6. Tabung dengan ukuran besar adalah outer capsule, sedangkan tabung dengan ukuran lebih kecil adalah inner capsule. 


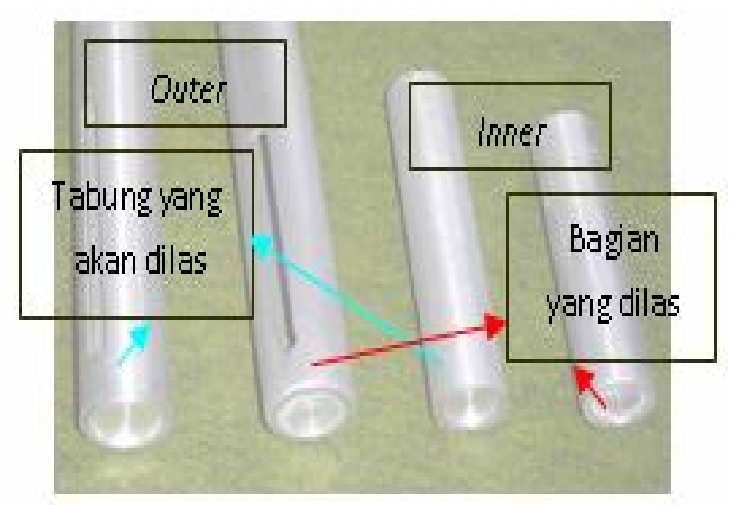

Gambar 6. Tabung Iradiasi

Tabel 1. Parameter-Parameter yang Diatur Dalam Pengelasan Otomatis

\begin{tabular}{|c|c|c|c|c|}
\hline \multirow{2}{*}{ No. } & \multirow{2}{*}{ PARAMETER } & \multicolumn{2}{|c|}{ CAPSULE } & \multirow{2}{*}{ Keterangan } \\
\hline & & Inner & Outer & \\
\hline 1. & Arus las (Amp) & $50 \mathrm{~A}$ & $60 \mathrm{~A}$ & \multirow{5}{*}{$\begin{array}{l}\text { Data-data tersebut } \\
\text { merupakan hasil } \\
\text { percobaan yang diambil } \\
\text { berdasarkan pendekatan } \\
\text { dari data-data pada } \\
\text { proses pengelasan } \\
\text { secara manual. }\end{array}$} \\
\hline 2. & Jarak torch dengan benda kerja & $1,6 \mathrm{~mm}$ & $1,6 \mathrm{~mm}$ & \\
\hline 3. & Waktu pelelehan & 5 detik & 7 detik & \\
\hline 4. & Waktu siklus pengelasan & 72 detik & 86 detik & \\
\hline 5. & $\begin{array}{l}\text { Kecepatan putaran motor } \\
\text { pemutar benda kerja }\end{array}$ & $0,9 \mathrm{rpm}$ & $0,9 \mathrm{rpm}$ & \\
\hline
\end{tabular}

\section{Uji Kebocoran}

Uji visual dilakukan dengan memeriksa bentuk pengelasan, kematangan hasil las, rongga-rongga kecil, dan sebagainya. Sedangkan uji kebocoran dilakukan dengan sebuah alat penguji yang disebut "bubble test" seperti terlihat pada Gambar 7.

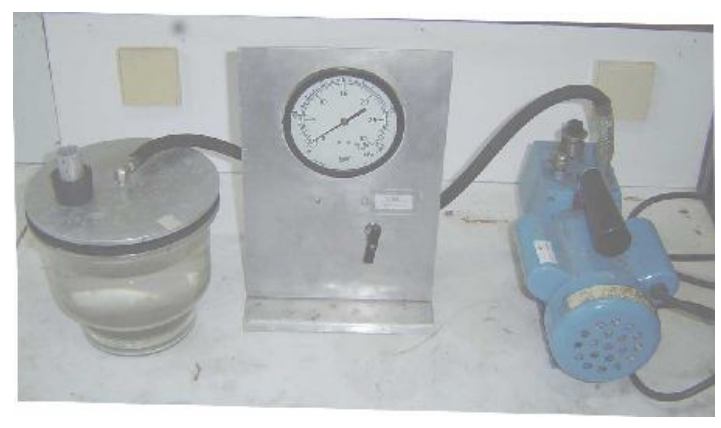

\section{Gambar 7. Alat Uji Kebocoran dengan Metode Bubble Test}

Prinsip kerjanya adalah benda kerja hasil pengelasan dimasukkan ke dalam wadah yang berisi air dan tertutup rapat oleh karet seal. Bagian yang dilas 
pada tabung iradiasi tercelup ke dalam air. Pompa vakum dihidupkan sehingga udara yang terdapat dalam wadah tersebut akan tertarik oleh pompa vakum. Apabila terdapat kebocoran pada tabung iradiasi maka pada air akan keluar gelembung-gelembung udara. Jika hasil pengelasan bagus (tidak terdapat kebocoran) maka dari dalam air tidak akan keluar gelembunggelembung udara.

Untuk tabung iradiasi yang dilakukan pengelasan secara otomatis, dilakukan uji coba kebocoran dengan tekanan vakum sampai dengan $28 \mathrm{inHg}$ dan dibiarkan selama 5 menit. Hasilnya adalah tidak terdapat gelembung udara dan tekanan masih bertahan sebesar 28 inHg. Dengan demikian tabung iradiasi tersebut layak untuk digunakan. Sehingga sistem kontrol pengelasan tabung iradiasi secara otomatis tersebut dapat dinyatakan berfungsi dengan baik.

\section{KESIMPULAN}

Sistem kontrol pengelasan tabung iradiasi secara otomatis telah dibuat dan setelah dilakukan uji fungsi, dapat beroperasi dengan baik. Hasil pengelasan pada inner capsule dan outer capsule dinyatakan layak untuk digunakan setelah melalui uji kebocoran. Agar diperoleh hasil pengelasan yang maksimal, maka harus diperhatikan bentuk tabung yang simetris (dipengaruhi oleh proses pembuatan serta penyimpanan) dan permukaan yang akan dilas harus bersih.

\section{DAFTAR PUSTAKA}

1. ANONIM, 1997, “Teknik Produksi Radioisotop”, Pusat Produksi RadioisotopBATAN,

2. ZAHIRUDIN, 1993, “Teknik Pemilihan Wadah Sasaran”, Pelatihan Teknologi Proses Produksi Radioisotop dan Senyawa Bertanda.

3. OMRON-INDONESIA, 1997, “OMRON Training Manual”, Omron-Indonesia Representative Office. 


\section{LAMPIRAN}

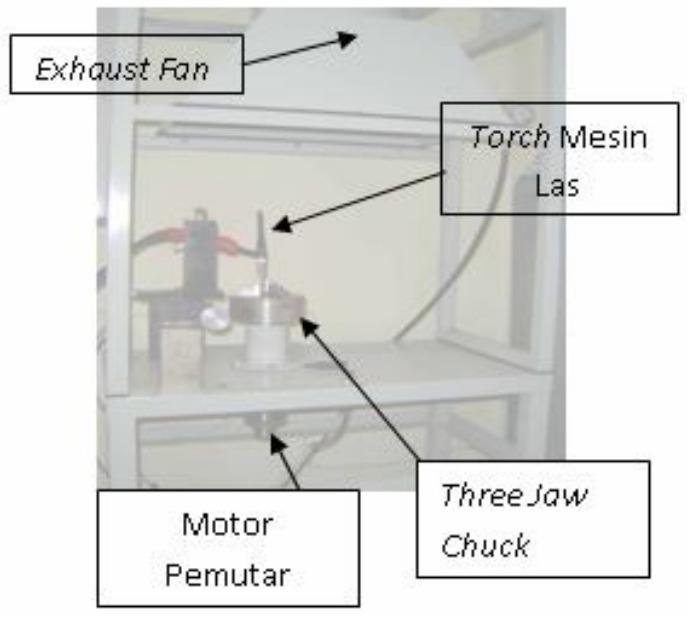

Meja Kerja yang terdiri dari Torch Mesin Las, Exhaust Fan, Three Jaw Chuck, dan Pemutar Benda Kerja

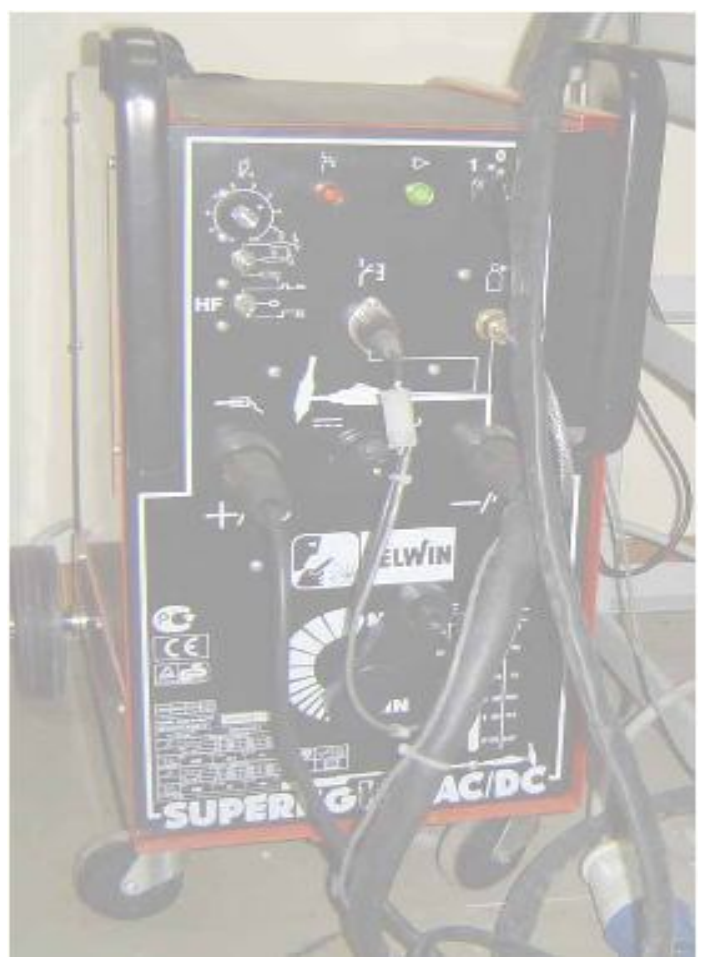

Mesin Las TIG 


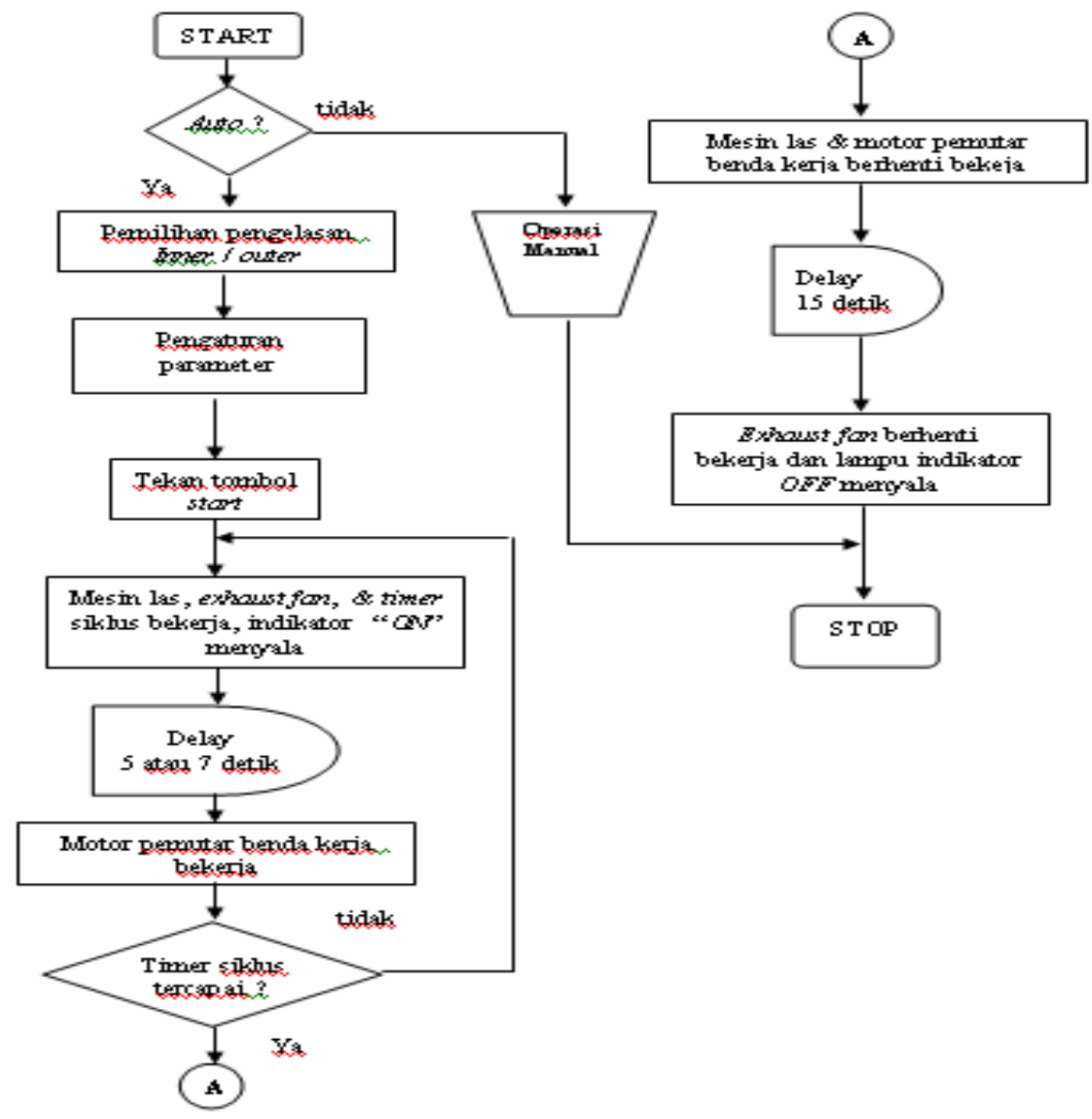

Flow Chart Proses Pengelasan Tabung Iradiasi secara Otomatis 
